\title{
Maintenance modelling and optimization in the industry 4.0 context: Applications to the maintenance and design of industrial vehicles
}

\author{
Segolene Clemence Marie Mosser ${ }^{1^{*}}$ \\ ${ }^{1}$ Mechanical Department, University of Technology of Belfort-Montbéliard, France \\ *Corresponding author: segolene.mosser@utbm.fr \\ (C) The Author \\ 2021. \\ Abstract \\ Published by \\ ARDA. \\ This paper focused on the maintenance problems encountered by industrial \\ vehicles within the Volvo Group. The main goal of the research on this subject \\ was to propose to customers' a personalized maintenance offer which adapts to \\ their constraints while reducing the impact on the operating costs. To achieve \\ this, a policy has been developed. This policy works on the dynamic gathering of \\ information using both the available monitoring information and the knowledge \\ of the multi-component system. Its objective is to guarantee to the customer the \\ autonomy of its system over given periods of operation while minimizing the \\ total cost of maintenance. The paper showed that the policy developed does \\ indeed reduce the total maintenance cost compared to the previous policy used \\ within the Volvo group. Nevertheless, this policy still has room for improvement.
}

Keywords: Maintenance, Industry 4.0, Optimization, Modelling, Vehicles

$\begin{array}{ll}\text { Abbreviations and symbols } \\ \text { AGAN } & \text { As Good As New } \\ C R(t) & \text { Replacement cost of system components over }[0, t] \\ C S C(t) & \begin{array}{l}\text { Extra cost associated with corrective maintenance when the system fails over the } \\ \text { time interval }[0, t]\end{array} \\ C S D(t) & \begin{array}{l}\text { Diagnostic overhead when the system fails over the time interval }[0, t] \\ \text { Total system maintenance cost over the time interval }[0, t]\end{array} \\ J_{w} & \text { Maintenance decision criterion with } w \text { the index of the decision criterion under } \\ L & \text { study } \\ \text { MFOP } & \text { Threshold limit of degradation of an entity } \\ \text { MRP } & \text { Maintenance Free Operating Period } \\ \text { MFOPS } & \text { Maintenance Recovery Period } \\ M F O P S(X, t) & \text { Maintenance Free Operating Period Survivability } \\ N C & \text { MFOPS of the } t \text { system after replacing the } X \text { assembly. } \\ R_{\text {syst }} & \text { Confidence level } \\ t & \text { System reliability } \\ X & \text { Time } \\ Z(t) & \text { A set of components to be replaced for a given solution } \\ Z p r e v & \text { Level of degradation of an entity } \\ \tau & \text { Preventive threshold of degradation }\end{array}$

This work is licensed under a Creative Commons Attribution License (https://creativecommons.org/licenses/by/4.0/ ) that allows others to share and adapt the material for any purpose (even commercially), in any medium with an acknowledgement of the work's authorship and initial publication in this journal. 


\section{Introduction}

More than ever, maintenance has a major place in the industry. Indeed, the demand for quality and productivity is growing. The product must be produced better and faster, without either of these two factors being put in the background. Industry 4.0 brings new constraints within the production system [1]. To seduce consumers, industrial companies offer unique and personalized products while maintaining profits, despite low manufacturing volumes. Thus, production must be adaptable and reactive quickly, which is a major challenge.

Maintenance is all the technical, administrative and management actions during the life cycle of an asset, intended to maintain or restore it to a state in which it can perform the required function [2]. A breakdown of a machine within a company can quickly cost the company millions of euros. This cost includes lost sales, delay costs that may be part of a contract and also maintenance costs. Thus, maintenance plays a major role in this industry 4.0. This maintenance advocates continuous improvement and suggests more and more advanced tools and methods [3].

Previously, maintenance was purely corrective. The failure was expected to react. Over time, maintenance has become more and more predictive, with systematic maintenance and conditional maintenance. Currently, maintenance is predictive [2]. This form of maintenance seeks to predict the evolution of the degradation of a tool during its operation and at the level of its design [4].

This paper was interested in the maintenance problems associated with industrial vehicles, focusing particularly on the planning of maintenance operations and the development of a design methodology for maintenance [5]. The goal of the studied application is to propose a maintenance offer personalized according to each vehicle and able to adapt to the constraints of the users. This offer tends both to guarantee a high level of availability and to reduce maintenance costs.

All this is based on a maintenance policy that aims to ensure, at a certain risk, the autonomy of a multicomponent system over given operation periods [6]. During these periods, no maintenance operation and no system failure must disrupt the realization of the missions. At the end of each period, the policy under consideration evaluates the necessity of a maintenance intervention to ensure the next period with a specified confidence level. When maintenance is deemed necessary, criteria integrating the costs and efficiency of maintenance are introduced to select the operations to be performed [7].

Simulation results are used to illustrate the methods developed. An application on a multi-component system is also carried out, which will allow comparison with models. The multi-component system considered refers to a sub-system of the industrial vehicle [8]. The objective is to apply the maintenance policy that has been developed considering the structure of the studied system and the available monitoring information [9].

\section{Method}

A maintenance policy has been developed in the framework of this study. This one is based on an existing maintenance policy: The Maintenance Free Operating Period (MFOP)[10][11]. However, some evolutions have been brought to this initial maintenance policy. This paper first looked at the maintenance policy to understand how it works. Then, it followed the development process [12] of the studied maintenance policy.

\subsection{The initial maintenance policy: Maintenance Free Operating Period (MFOP)}

First, the paper defined the three main quantities associated with the MFOP:

- Maintenance Free Operating Period (MFOP)[13]

- Maintenance Recovery Period (MRP)

- Maintenance Free Operating Period Survivability (MFOPS)

The Maintenance Free Operating Period (MFOP) represents a period of operation during which the equipment must be able to carry out its assigned missions without maintenance action and without the operator being restricted in any way due to system failures [14] or limitations [15].

In other words, the MFOP defines a period of operations without interruption due to unplanned maintenance. The interest of the MFOP is to be interested in the whole life of the system by not applying only on new systems. This definition does not prohibit failures in a global way. Indeed, they can appear on some components of the system as long as the progress of the mission is not affected. In an ideal policy based on the MFOP, corrective maintenance must be bypassed [16]. To do this, planned maintenance periods must be defined between MFOPs. This is called the Maintenance Recovery Period (MRP). 
The Maintenance Recovery Period (MRP) is defined as the period during which appropriate maintenance is performed on the system to enable it to successfully complete the next MFOP [17][18]. This maintenance period following an MFOP or several MFOP cycles is flexible in length. The length of the downtime will depend on the extent of the maintenance work to be performed [19]. Obviously, in practice it is impossible to guarantee $100 \%$ that no failure will occur on the next MFOP. Therefore, it is crucial to assess this risk with the Maintenance Free Operating Period Survivability (MFOPS).

Maintenance Free Operating Period Survivability (MFOPS) is the probability that the system will survive for the duration of the MFOP knowing that it was in an operating state at the beginning of the period [20].

Assuming a MFOP of length $t_{M F O P}$ units of time, the probability at time $t$ that the system will survive $t_{M F O P}$ knowing that it is in an operating state is given by:

$$
\operatorname{MFPOS}(t)=\frac{R_{\text {syst }} \times\left(t+t_{\text {MFOP }}\right)}{R_{\text {syst }}}
$$

With $R_{\text {syst }}(t)$ the reliability of the system at time $t$. Note that $t$ and $t_{M F O P}$ can also be defined in kilometric units in the transportation field.

MFOP specifies the needs of customers in a clear manner [21]. It consists of ensuring that users have autonomy over given periods of operation. To do this, the MFOP shifts virtually all future corrective maintenance to planned periods of preventive maintenance. This feature maximizes the operational availability of systems[22]. By avoiding unplanned downtime as much as possible, MFOP reduces system repair costs but also logistical support by reducing the need to reschedule missions[15]. This concept facilitates the management of spare parts by reducing uncertainty in the planning of maintenance operations.

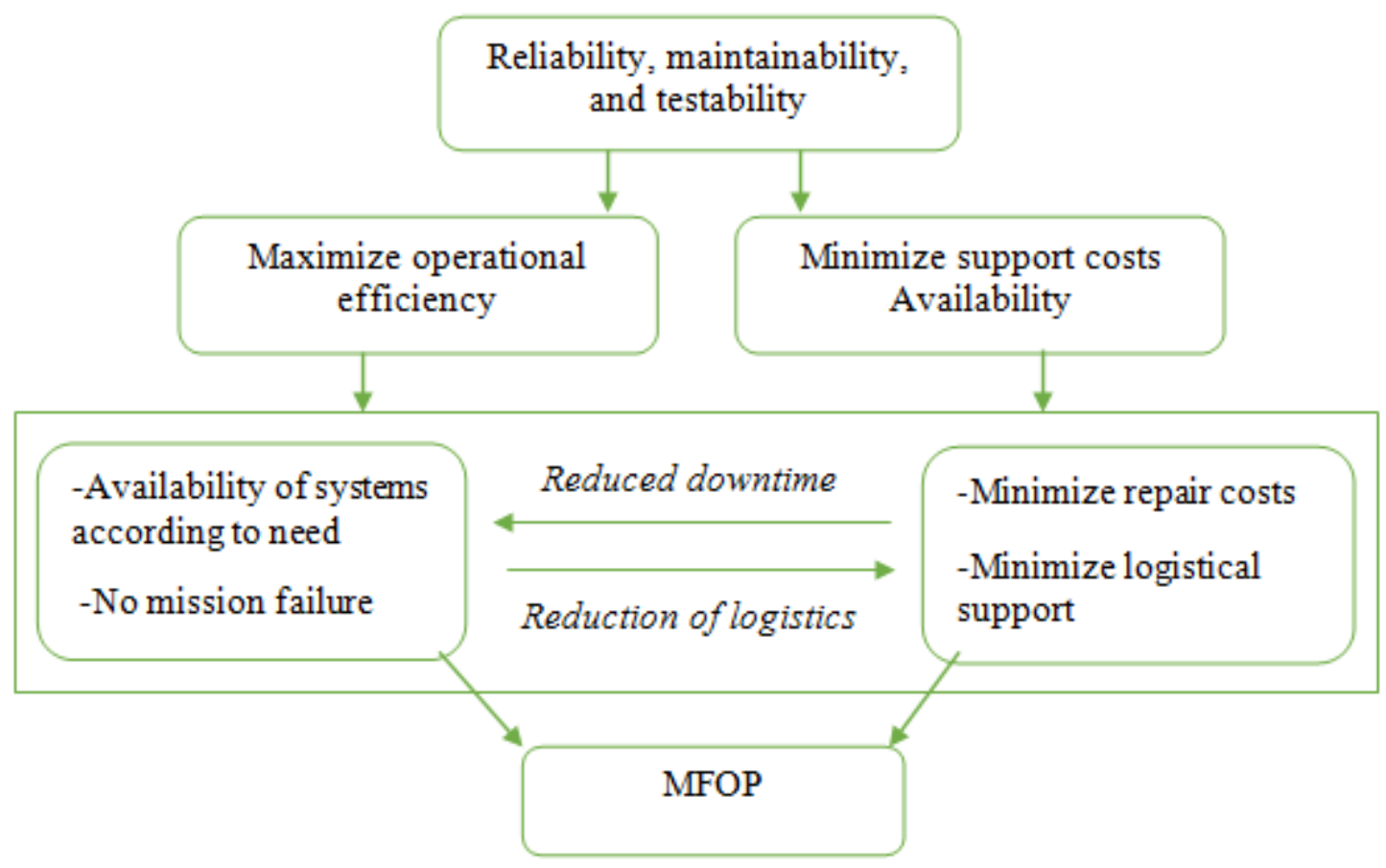

Figure 1. Motivation for the MFOP [10]

\subsection{The maintenance policy developed}

This section aims to present the maintenance policy developed. First, let us specify that the construction of this policy is based on the constraints of the truck industry [23]. The policy developed aims at ensuring the proper functioning of a multi-component system [24] over a given period of time with a specified level of confidence. To do so, it evaluates, at the end of each operational period, the need to maintain the system. If maintenance is deemed necessary, the policy selects the operations to be performed. Contrary to most of the works developed on the MFOP concept, this policy is dynamic[25]. This means that the maintenance decision is adapted according to the monitoring information available online[26]. 
In this policy, the objective is to avoid downtime of the system in operation. To achieve this goal, this concept aims to move all future corrective maintenance to planned preventive maintenance periods (MRP). These features are well suited to the constraints of transportation systems where the number of maintenance opportunities is limited and where downtime has strong financial consequences[27]. In addition, will integrate the possibilities offered by new information and communication technologies within this policy[28]. Thanks to the monitoring information, the maintenance decision is no longer static but based on the current state of the system.

The proposed policy can adapt to the structure of the multi-component system. It should be noted that our study focuses on systems with an elementary structure, made of non-repairable components. For these systems, only component replacements are allowed. The paper also assumes that the replacement allows the component to recover its initial state (AGAN).

Here are the steps of the decision process and thus the functioning of the developed maintenance policy:

- Step 1 of the decision process: define at time $t$ the necessity of a maintenance intervention on the system. The instant $t$ represents either the end of a MFOP or a failure at the system level.

To make this decision, the paper seeks to evaluate the probability that the system will operate until the end of the next MFOP, knowing the information available at $t$. This paper assumes, at a minimum, that the information about the operation of the multi-component system is known at time $t$.

- If it is running, this probability is the $\operatorname{MFOPS}(t)$.

- If the system is down, the $M F O P S(t)$ is zero.

- Step 2 of the decision process: compare the MFOPS $(t)$ of the system with a specified confidence level $N C$ :

- If $\operatorname{MFOPS}(t)>N C$, the decision process considers the maintenance intervention not necessary.

- If $M F O P S(t)<N C$, maintenance intervention is deemed essential

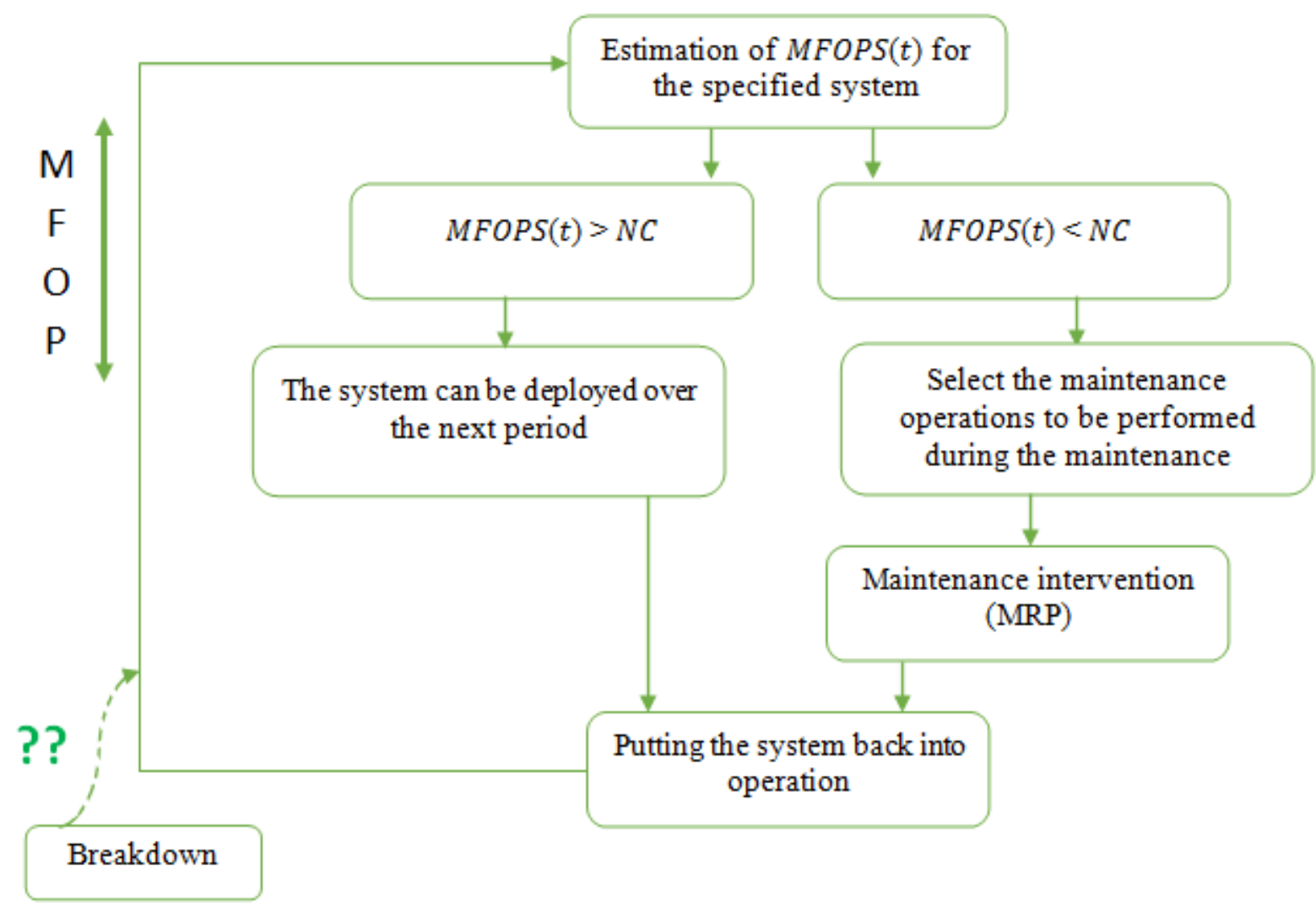

Figure 2. Summary of the maintenance policy developed

When a maintenance intervention is required, it is necessary to identify the components to be replaced so that the system can ensure the next MFOP with the required confidence level. In this framework, a constrained 
optimization[29] problem is introduced to select the replacements to be performed. In general, the problem can be expressed as:

$$
\min _{\{\mathrm{X}\}} J_{w}(X) \text { avec } \operatorname{MFOPS}(X, t)>N C
$$

with $X$ a set of components to be replaced for a given solution, $J w$ the maintenance decision criterion with $w$ the index of the decision criterion under study, MFOPS $(X, t)$ the MFOPS of the system at $t$ after replacement of set $X$, and $N C$ the level of confidence to be achieved on the next MFOP.

\subsection{Application to an industrial vehicle subsystem}

The developed maintenance policy has been applied within a multi-component system[30]. The multicomponent system considered refers to a sub-system of the industrial vehicle. The name of this system is not specified due to a confidentiality problem. The objective is to apply the developed maintenance policy considering the structure of the studied system and the available monitoring information[31]. This application has been carried out in the framework of an internal research project within the Volvo Group[32].

\section{Results and discussion}

\subsection{Results from the maintenance model developed}

Simulations were set up to estimate the total maintenance costs $C T M(t)$. Note that the total system maintenance cost $\operatorname{CTM}(t)$ is calculated over a finite time horizon. This horizon is set to 5 years, which corresponds to the nominal duration of a maintenance contract for an industrial vehicle. This cost $C T M(t)$ is broken down as follows :

$$
\operatorname{CTM}(t)=\operatorname{CR}(t)+\operatorname{CSC}(t)+\operatorname{CSD}(t)
$$

With $C R(t)$ the cost of replacing system components over $[0, t], \operatorname{CSC}(t)$ the extra cost associated with corrective maintenance when the system fails over $[0, t]$, and finally $\operatorname{CSD}(t)$ the extra cost associated with diagnosis when the system fails over $[0, t]$.

The simulations performed are based on the Monte Carlo method and are performed over a 5-year horizon. The purpose of the Monte Carlo method is to calculate a numerical value using random processes, i.e. probabilistic techniques. Let's consider that the studied system travels on average $100000 \mathrm{~km}$ per year. Moreover, the MFOP is fixed at $50000 \mathrm{~km}$. This value of the MFOP coincides with the objective of the Volvo group which is to have, at most, two maintenance stops per year.

To define the optimal parameters of the maintenance policy, simulations are performed considering a confidence level NC ranging from $30 \%$ to $85 \%$ with a step of $5 \%$. At the monitoring information level, degradation measurements are available for 4 defined components in the system. The results suggest that for a MFOP set at $50000 \mathrm{~km}$, an optimal CTM of $7232 €$ is obtained for a $N C=50 \%$ as it can be seen in the following figure.

\section{Total cost of maintenance for different confidence levels (MFOP $=$ $50000 \mathrm{~km})$}

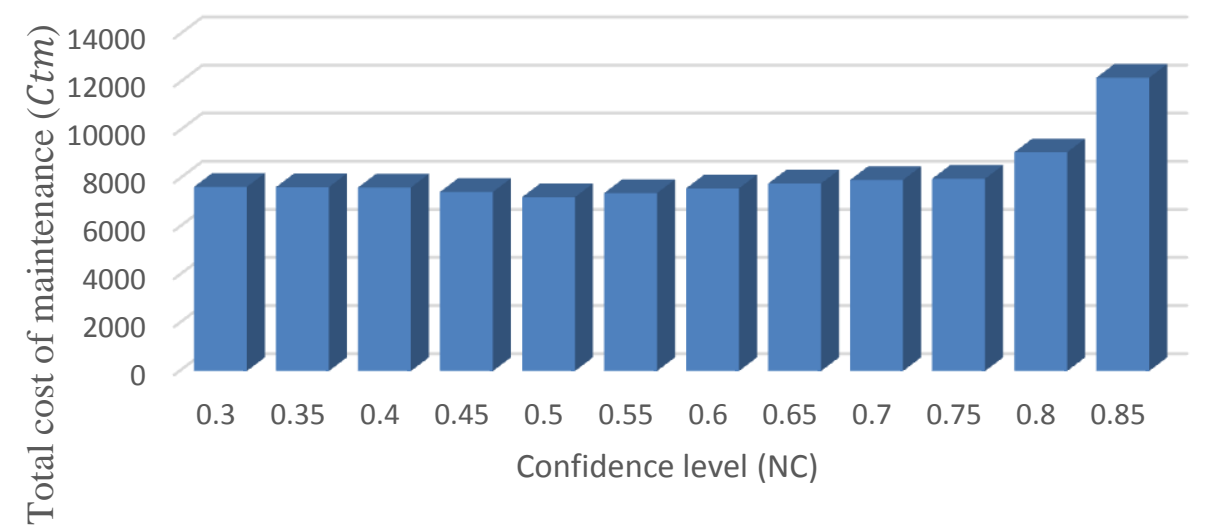

Figure 3. Total cost of maintenance for different confidence levels (MFOP $=50000 \mathrm{~km}$ ) 


\subsection{Comparison with the policy used within the company}

In order to evaluate the policy currently applied on this system and to be able to compare it with the one presented in this paper, a maintenance model must be built. Let us consider, first of all, that the reliability properties as well as the costs and durations have been fixed for each component of the system thanks to a reliability model. The knowledge of this reliability structure is necessary to manage the assets. The system is composed of 18 components and it is the same as the one seen in the previous part. Thus, degradation measures are available for the same 4 components as in the previous part. Finally, the cost model needed to evaluate $C T M(t)$ is similar to the one used previously.

In terms of maintenance policy, this is essentially corrective. The Volvo Group considers that most of the components of this system should not fail over the period covered by the maintenance contract. A conditional preventive maintenance policy is applied only on the 4 same components used in the previous part which will be named $\{$ A15, A16, A17, A18\}.

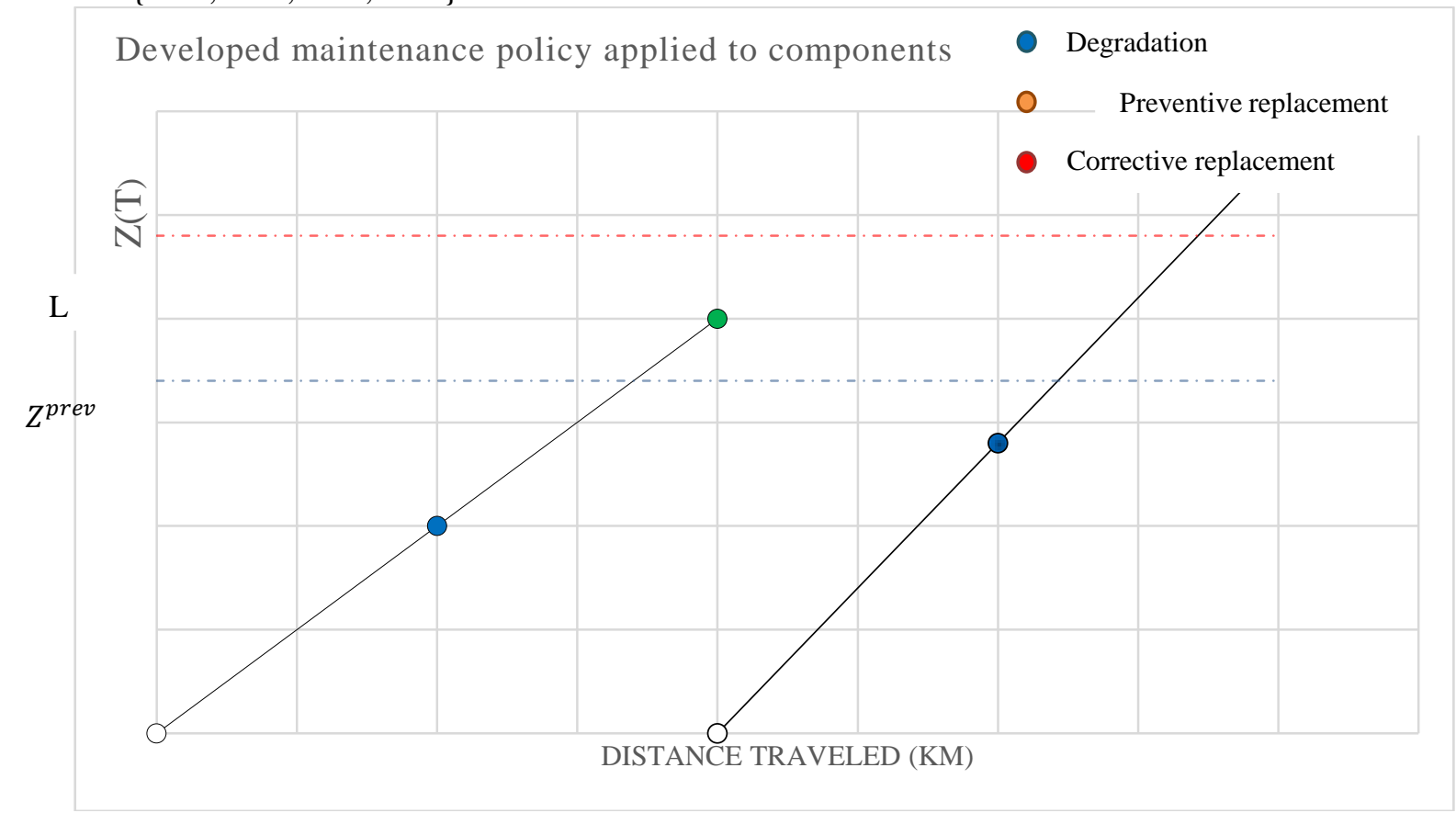

Figure 4. Developed maintenance policy applied to components

To model the maintenance decision process, assume that degradation information is reported every $\tau=50,000 \mathrm{~km}$ for these four components. Let us also assume that the degradation of these components is known when the system is down. A preventive degradation threshold Zprev, defined thanks to the technical specifications, is considered for each component. This is $Z_{A 15}^{\text {prev }}=Z_{A 16}^{\text {prev }}=26$ for components $\{\mathrm{A} 15, \mathrm{~A} 16\}$ and $Z_{A 17}^{\text {prev }}=Z_{A 18}^{\text {prev }}=5.8$ for components $\{\mathrm{A} 17, \mathrm{~A} 18\}$. Note that $Z(t)$ is the degradation level of an entity and $L$ is the threshold limit of degradation of an entity. Depending on the available information, several cases can be listed for a component:

- If the degradation information indicates that $Z(t)<Z$ prev, no maintenance is performed at time $t$ on the component.

- If the degradation information indicates that $L>Z(t)>Z$ prev, the component is still operating but preventive maintenance is deemed necessary and should be performed at timet.

- As soon as $Z(t)>L$, the component is no longer functioning. Depending on the structure and state of the system, this component is replaced either at the next available degradation information or when the system is down.

For other components undergoing corrective maintenance, no information is available. Nevertheless, a diagnosis is performed on all components when the system is immobilized. This allows to identify the components in failure and to trigger their replacement. To evaluate the CTM of this system subject to the current maintenance policy, the Monte Carlo method is applied. 


\begin{tabular}{lccc}
\hline $\begin{array}{c}\text { Current maintenance } \\
\text { policy }\end{array}$ & $\begin{array}{c}\text { Maintenance policy based on the } \\
\text { MFOP (the policy developed) }\end{array}$ & Gain \\
\hline $\boldsymbol{C}_{\boldsymbol{t m}}$ & 7736 & 7232 & $6.5 \%$ \\
\hline
\end{tabular}

Table 1. Comparison of the total maintenance cost

$C_{t m}$ of the two maintenance policies considered.

Table 1 compares the CTM(t) obtained by considering the current maintenance policy and the MFOP-based maintenance policy. Thus, the maintenance policy developed in this manuscript results in a reduction of more than $6 \%$ in $C T M(t)$ compared to the current situation. This decrease in maintenance cost is mainly explained by a drastic reduction in fixed assets of more than $14 \%$. These results thus allow to justify the added value of the maintenance policy developed in this manuscript on a real system. The policy based on the MFOP also leads to a slight decrease in the cost dispersion for the simulated individuals.

\section{Conclusions}

This paper have been interested in the maintenance problems encountered by industrial vehicles from the Volvo Group. These industrial vehicles are considered as multi-component systems. The research has been focused on the planning of maintenance operations and the development of a design methodology for maintenance. These schedules are static because the information used is not updated during the life of the vehicle. Maintenance operations are planned at regular intervals and each component is considered independently of the system. Finally, the feedback from maintenance activities is only minimally considered to improve the design of the vehicles.

The objective of this research was to propose a customized maintenance offer according to the real use of the system and adapted to the constraints of the customers. This offer is intended to guarantee a high level of system availability while reducing the impact of maintenance on operating costs.

In this context, a dynamic maintenance policy has been developed for multi-component systems. Its function is to ensure, with a certain risk, the autonomy of the system over given periods of operation. These periods, called MFOP, allow users to perform their missions without being disturbed by system failures or maintenance operations. At the end of each period, the decision process evaluates the necessity of a maintenance intervention to guarantee the next MFOP with a specified confidence level. When maintenance is deemed necessary, a constrained optimization problem has been considered to select the replacements to be performed. Decision criteria based on the replacement costs and on the overall efficiency of the maintenance operations were introduced.

The developed maintenance policy has been applied on a real system. This implementation required different necessary steps. To do so, reliability models were built. This application also required some adjustments to the maintenance policy to be considered. The results of the simulations carried out on the real system made it possible to verify the added value of the developed policy on the total cost of maintenance in comparison with the current policy.

They remain short- and medium-term perspectives for this project. In the short term, the perspectives consist mainly in extending the work done by lifting the simplifying assumptions used in the modeling. In this paper, the different works and results presented were obtained on a simulation platform. The longer-term technological perspective consists in moving from this simulation platform to the implementation on a real system. In other words, it is necessary to determine by which technological means we can implement the developments carried out.

\section{References}

[1] E. Barlow, T. Bedford, M. Revie, J. Tan, and L. Walls, "A performance-centred approach to optimising maintenance of complex systems," Eur. J. Oper. Res., Jul. 2020, doi: 10.1016/j.ejor.2020.11.005.

[2] R. Mobley, "An introduction to predictive maintenance." Buttherworth-Heinemann, 2002.

[3] S. H. Ding and S. Kamaruddin, "Maintenance policy optimization-literature review and directions," International Journal of Advanced Manufacturing Technology, vol. 76, no. 5-8. Springer London, pp. 
1263-1283, Feb. 01, 2015, doi: 10.1007/s00170-014-6341-2.

[4] A. Sánchez-Herguedas, A. Mena-Nieto, and F. Rodrigo-Muñoz, "A new analytical method to optimise the preventive maintenance interval by using a semi-Markov process and z-transform with an application to marine diesel engines," Reliab. Eng. Syst. Saf., vol. 207, p. 107394, Mar. 2021, doi: 10.1016/j.ress.2020.107394.

[5] H. Wang, "A survey of maintenance policies of deteriorating systems," Eur. J. Oper. Res., vol. 139, no. 3, pp. 469-489, Jun. 2002, doi: 10.1016/S0377-2217(01)00197-7.

[6] R. Lesobre, "Modélisation et optimisation de la maintenance et de la surveillance des systèmes multicomposants-Applications à la maintenance et à la conception de véhicules industriels," Université Grenoble Alpes, Mar. 2015. Accessed: Mar. 20, 2021. [Online]. Available: https://tel.archivesouvertes.fr/tel-01169295.

[7] M. Alimian, V. Ghezavati, and R. Tavakkoli-Moghaddam, "New integration of preventive maintenance and production planning with cell formation and group scheduling for dynamic cellular manufacturing systems," J. Manuf. Syst., vol. 56, pp. 341-358, Jul. 2020, doi: 10.1016/j.jmsy.2020.06.011.

[8] L. Bian, G. Wang, and P. Liu, "Reliability analysis for multi-component systems with interdependent competing failure processes," Appl. Math. Model., vol. 94, pp. 446-459, Jun. 2021, doi: 10.1016/j.apm.2021.01.009.

[9] C. Liu, Y. Li, Q. Wang, and W. Mou, "A synchronous association approach of geometry, process and monitoring information for intelligent manufacturing," Robot. Comput. Integr. Manuf., vol. 58, pp. 120-129, Aug. 2019, doi: 10.1016/j.rcim.2019.02.007.

[10] J. Long, R. A. Shenoi, and W. Jiang, "A reliability-centred maintenance strategy based on maintenance-free operating period philosophy and total lifetime operating cost analysis," Proc. Inst. Mech. Eng. Part G J. Aerosp. Eng., vol. 223, no. 6, pp. 711-719, Jun. 2009, doi: 10.1243/09544100JAERO488.

[11] J. Long and W. Jiang, "A method for maintenance scheduling in manufacturing systems based on TPM and MFOP," in Applied Mechanics and Materials, 2011, vol. 44-47, pp. 404-408, doi: 10.4028/www.scientific.net/AMM.44-47.404.

[12] "The Development Process: A Spatial Perspective - Akin Mabogunje - Google Livres." https://books.google.fr/books?hl=fr\&lr=\&id=8KE0CwAAQBAJ\&oi=fnd\&pg=PP1\&dq=DEVELOP MENT+PROCESS\&ots=A4GBx5yEhZ\&sig=aj1jx2lfH0KBsL78gp3FcCliOcM\&redir_esc=y\#v=one page \&q=DEVELOPMENT PROCESS\&f=false (accessed Apr. 19, 2021).

[13] J. Long, R. A. Shenoi, and W. Jiang, "A reliability-centred maintenance strategy based on maintenance-free operating period philosophy and total lifetime operating cost analysis," Proc. Inst. Mech. Eng. Part G J. Aerosp. Eng., vol. 223, no. 6, pp. 711-719, Jun. 2009, doi: 10.1243/09544100JAERO488.

[14] K. Korsah, M. D. Muhlheim, and D. Holcomb, "Industry Survey of Digital I\&C Failures Salt Cooled Reactor Design View project Low cost, accurate method of online gas analysis for incipient failure monitoring of power transformers View project." Accessed: Apr. 19, 2021. [Online]. Available: http://www.osti.gov/contact.html.

[15] C. J. Hockley, “Design for success,” Proc. Inst. Mech. Eng. Part G J. Aerosp. Eng., vol. 212, no. 6, pp. 371-378, Jun. 1998, doi: 10.1243/0954410981532342.

[16] "Maintenance for Industrial Systems - Riccardo Manzini, Alberto Regattieri, Hoang Pham, Emilio Ferrari Google

Livres." https://books.google.fr/books?hl=fr\&lr=\&id=hsDLD3UHrGgC\&oi=fnd\&pg=PA1\&dq=Manzini,+R., + Regattieri,+A.,+Pham, + H.,+\%26+Ferrari,+E.+(2010).+Maintenance+for+industrial+systems+.Sprin ger+Verlag+.\&ots=1HFjT5rd_B\&sig=11m5EJVxjgGqyzPIKQazJTv2NkY\&redir_esc $=y \# v=o n e p a g e$ $\& q \& \mathrm{f}=$ false (accessed Apr. 19, 2021).

[17] U. D. Kumar, "New trends in aircraft reliability and maintenance measures," J. Qual. Maint. Eng., vol. 5, no. 4, pp. 287-295, 1999, doi: 10.1108/13552519910298046.

[18] P. F. Cini and P. Griffith, "Designing for MFOP: Towards the autonomous aircraft," J. Qual. Maint. Eng., vol. 5, no. 4, pp. 296-306, 1999, doi: 10.1108/13552519910298055.

[19] "Application of the aviation derived maintenance free operating period concept in the South African mining industry." http://www.scielo.org.za/scielo.php?pid=S222478902013000300013\&script=sci_arttext\&tlng=es (accessed Apr. 19, 2021). 
[20] U. Dinesh Kumar, J. Knezevic, and J. Crocker, "Maintenance free operating period - an alternative measure to MTBF and failure rate for specifying reliability?," Reliab. Eng. Syst. Saf., vol. 64, no. 1, pp. 127-131, Apr. 1999, doi: 10.1016/S0951-8320(98)00048-9.

[21] P. Mitchell, "Defense Technical Information Center Compilation Part Notice TITLE: Design for Low Cost Operation and Support [la Conception en," Sep. 2000. Accessed: Apr. 19, 2021. [Online]. Available: https://apps.dtic.mil/sti/citations/ADP010429.

[22] G. A. Pryor, "Methodology for Estimation of Operational Availability as Applied to Military Systems," Jan. 2008. Accessed: Apr. 19, 2021. [Online]. Available: https://apps.dtic.mil/sti/citations/ADA518378.

[23] J. Santos, R. M. Gouveia, and F. J. G. Silva, "Designing a new sustainable approach to the change for lightweight materials in structural components used in truck industry," J. Clean. Prod., vol. 164, pp. 115-123, Oct. 2017, doi: 10.1016/j.jclepro.2017.06.174.

[24] K. Verbert, B. De Schutter, and R. Babuška, "Timely condition-based maintenance planning for multi-component systems," Reliab. Eng. Syst. Saf., vol. 159, pp. 310-321, Mar. 2017, doi: 10.1016/j.ress.2016.10.032.

[25] R. E. Wildeman, R. Dekker, and A. C. J. M. Smit, "A dynamic policy for grouping maintenance activities," Eur. J. Oper. Res., vol. 99, no. 3, pp. 530-551, Jun. 1997, doi: 10.1016/S03772217(97)00319-6.

[26] E. J. Johnson, J. W. Payne, D. A. Schkade, and J. R. Bettman, "Monitoring Information Processing and Decisions: The Mouselab System," Feb. 1989. Accessed: Apr. 19, 2021. [Online]. Available: https://apps.dtic.mil/sti/citations/ADA205963.

[27] A. Evans and A. Schäfer, "The impact of airport capacity constraints on future growth in the US air transportation system," J. Air Transp. Manag., vol. 17, no. 5, pp. 288-295, Sep. 2011, doi: 10.1016/j.jairtraman.2011.03.004.

[28] C. J. Hamelink, "NEW INFORMATION AND COMMUNICATION TECHNOLOGIES, SOCIAL DEVELOPMENT AND CULTURAL CHANGE," 1997.

[29] M. W. Krentel, "The complexity of optimization problems," J. Comput. Syst. Sci., vol. 36, no. 3, pp. 490-509, Jun. 1988, doi: 10.1016/0022-0000(88)90039-6.

[30] T. Xia, L. Xi, X. Zhou, and J. Lee, "Dynamic maintenance decision-making for series-parallel manufacturing system based on MAM-MTW methodology," Eur. J. Oper. Res., vol. 221, no. 1, pp. 231-240, Aug. 2012, doi: 10.1016/j.ejor.2012.03.027.

[31] R. Prytz, S. Nowaczyk, T. Rögnvaldsson, and S. Byttner, "Predicting the need for vehicle compressor repairs using maintenance records and logged vehicle data," Eng. Appl. Artif. Intell., vol. 41, pp. 139150, May 2015, doi: 10.1016/j.engappai.2015.02.009.

[32] "Involving middle managers in strategy at Volvo Group - ProQuest." https://search.proquest.com/openview/d3bb169e7c73cb8228d6ea300b24a56c/1?pqorigsite $=$ gscholar $\& \mathrm{cbl}=44514($ accessed Apr. 19, 2021) . 